\title{
The Impact of Radiation Therapy Variables on Pediatric High-Grade Glioma Outcomes: A National Cancer Database Analysis
}

\section{Christopher Williamson}

Emory University Winship Cancer Institute https://orcid.org/0000-0001-6336-9049

\section{Shayla Williamson}

University of Pittsburgh School of Information Sciences

\section{Renjian Jiang}

Emory University

\section{Lisa Sudmeier}

Emory University

\section{Natia Esiashvili}

Emory University

Bree R. Eaton ( $\sim$ brupper@emory.edu )

Emory University

\section{Research Article}

Keywords: High-grade gliomas, astrocytoma, glioblastoma, pediatric, radiation therapy

Posted Date: June 18th, 2021

DOI: https://doi.org/10.21203/rs.3.rs-435118/v1

License: (c) (i) This work is licensed under a Creative Commons Attribution 4.0 International License. Read Full License

Version of Record: A version of this preprint was published at International Journal of Radiation Oncology*Biology*Physics on November 1st, 2020. See the published version at https://doi.org/10.1016/j.jirobp.2020.07.597. 


\section{Abstract \\ Purpose}

Pediatric high-grade glioma (HGG) is a devastating disease with a poor prognosis. The purpose of this analysis is to evaluate the impact of Radiation Therapy (RT) variables on outcomes of pediatric HGG patients in the National Cancer Database (NCDB).

\section{Methods}

The NCDB was used to select patients age $<22$ with histologically proven WHO Grade III and IV gliomas treated with $\geq 50$ Gy and < 76Gy RT between 2004 and 2013. RT variables including RT dose, timing between diagnosis and RT initiation ( $<4$ weeks, 4- 6 weeks, or $>6$ weeks), and RT modality were analyzed along with baseline demographic, tumor and treatment variables to assess the impact on overall survival in univariate and multivariable analyses.

\section{Results}

498 pediatric HGG patients were included. Histologies included glioblastoma (30\%), astrocytoma (55\%), oligogendroglioma (5\%) and gliomas not otherwise specific (10\%). The median RT dose was 59.4 Gy (SD $2.9 \mathrm{~Gy}$ ) starting a median of 4.4 weeks from diagnosis (SD 2.5 weeks). Median follow-up was 19.6 months with 1 - and 3 -year OS of $78.4 \%$ and $40.4 \%$, respectively. On Multivariable analysis, female gender, older age, and private insurance remained independently associated with lower rate of overall death. Radiation initiation $\leq 4$ weeks from diagnosis, and glioblastoma histology were significantly associated with higher rate of overall death. There was no relationship between radiation dose or whether radiation was delivered with proton or photon therapy and overall survival.

\section{Conclusions}

Outcomes for pediatric HGG are poor. Early initiation of RT within 4 weeks from diagnosis was negative associated with overall survival and may be related to unknown prognostic factors.

\section{Introduction}

In the United States, brain tumors are the most common pediatric solid tumor and the leading cause of cancer related death in children less than 14 years old [1]. Pediatric high-grade gliomas (HGG), including most commonly anaplastic astrocytoma, diffuse astrocytoma and glioblastoma are rare, aggressive glial cell tumors that account for less than $20 \%$ of brain tumors in the pediatric population [2]. These tumor types are classified by the World Health Organization as Type III or IV, signifying them as highly malignant with tumor characteristics of hypercellularity, nuclear atypia, and highly metabolic activity [3]. 
Pediatric HGGs are biologically distinct from adult glioblastoma yet share the same poor prognosis. In adult patients, maximal safe surgical resection followed by radiotherapy (RT) with concurrent and adjuvant temozolomide remains the current standard of care [4]. In pediatric HGG no clear standard exists, though a similar management strategy is often employed [5]. An initial prospective, randomized study dating back to 1989 showed an increased 5-year progression-free survival and overall survival for patients receiving radiotherapy with the addition of chemotherapy compared to RT alone [6]. Subsequent studies have further investigated a variety of post-surgical chemotherapy regimens in combination with RT without a clear benefit, and ongoing protocols continue to test novel systemic agents in molecular defined cohorts of pediatric HGG.

Despite the varying systemic therapy used, RT has remained a standard of care in the definitive management of pediatric HGG, though data addressing the impact of varying RT variables such as dose, technique, and timing are lacking. The purpose of this analysis is to evaluate the impact of RT variables on outcomes of pediatric patients with HGG treated with definitive RT in the National Cancer Database.

\section{Methods And Materials}

\section{Patient selection}

The National Cancer Database (NCDB) is a clinical oncology database supported by the American College of Surgeons and the American Cancer Society. The database includes hospital registry data aggregated from over 1500 Commission on Cancer (CoC) accredited hospitals and representing more than 70 percent of newly diagnosed cancer cases in the United States. Using information from the NCDB participant user data file containing pediatric and adult brain tumor cases diagnosed between 20042013, patients who met the following inclusion criteria were selected for this analysis: pediatric patients age $<22$, brain tumor location codes excluding the brainstem (ICD-0-3 C710-C719), histologically proven WHO Grade III and IV high-grade gliomas (astrocytomas, glioblastomas, astroblastomas and oligodendrogliomas) diagnosed between 2004 and 2013, receipt of RT within 90 days of diagnosis, and RT doses of $\geq 50 \mathrm{~Gy}$ and $<76 \mathrm{~Gy}$. This identified 208,559 patients and 208,061 patients were excluded for the reasons as detailed in Table 1. The final cohort included 498 patients. 
Patient Selection and Exclusion Criteria

\begin{tabular}{|c|c|c|}
\hline Selection and Exclusion Criteria & $\begin{array}{l}\text { Sample } \\
\text { Size }\end{array}$ & Excluded \\
\hline NCDB Brain PUF Cancer Cases & 208559 & - \\
\hline Age $<22$ & 23530 & 185029 \\
\hline Exclude brain stem & 19778 & 3752 \\
\hline Histology of gliomas & 5173 & 14605 \\
\hline Exclude in situ or borderline & 5112 & 61 \\
\hline Grade $3-4$ & 1138 & 3974 \\
\hline Received Adjuvant RT at least 50 Gy and less than 76 Gy & 659 & 479 \\
\hline Patients with glioma as 1 st or only primary cancer & 633 & 26 \\
\hline Exclude patients without follow up data & 566 & 67 \\
\hline $\begin{array}{l}\text { Patients who received all treatments at a facility other than facility that } \\
\text { reported cancer case }\end{array}$ & 558 & 8 \\
\hline Exclude patients who did not have pathologic confirmation & 555 & 3 \\
\hline Include patients with known chemotherapy treatment status & 539 & 16 \\
\hline Exclude Radiation started 90 days after diagnosis & 498 & 41 \\
\hline
\end{tabular}

\section{Independent Variables}

Radiation treatment parameters used as independent variables for outcomes analysis included radiation timing in weeks from diagnosis until RT initiation, radiation dose, and radiation modality. Radiation modality was defined as either proton therapy, IMRT photon RT, 3D conformal photon RT, or photon RT not otherwise specified (NOS). Radiation timing was categorized as $<4$ weeks, between 4 and 6 weeks, and greater than 6 weeks from diagnosis. The cumulative radiation dose including the sum of any dose described as "regional" or "boost" was analyzed as a continuous variable and defined as escalated (> $59.4 \mathrm{~Gy}$ ) vs. non-escalated ( $\leq 59.4 \mathrm{~Gy}$ ). Additional treatment variables including surgical resection, receipt of chemotherapy, whether chemotherapy was single agent or multi-agent, and chemotherapy sequence with radiation therapy were also evaluated along with demographic and tumor characteristics.

\section{Statistical Analyses}

Radiation treatment parameters as well as other treatment variables, demographic and tumor characteristics were presented with descriptive statistics. Univariate and multivariate Cox-proportional hazard regression models were fitted to evaluate the relationships between the radiation treatment 
parameters and patient characteristics with overall survival. Kaplan-Meier Curves were generated and compared by Log-rank tests for histology subtype and RT Delay. Similar set of analyses described above were conduct in the sub-cohort of patients who all received definitive surgical treatment, as a sensitivity test for the robustness of the effect estimates of RT delay. All analyses were conducted with SAS 9.4 (SAS Institute, Inc., Cary, North Carolina) and SAS macros developed by the Biostatistics and Bioinformatics and Winship Research Informatics Shared Resources at Winship Cancer Institute in Atlanta, Georgia [7], with a significant level of 0.05 .

\section{Results}

\section{Patient Population}

498 pediatric HGG patients were included in this analysis. Demographic and tumor characteristics, and treatment variables are shown in Tables 2 and 3, respectively. The median age at diagnosis was 15 years (range $0-21$ ) and $54 \%$ of patients were male. The majority of patients were white (79\%) and living in a metro area (80\%). The most common histologies were astrocytoma (55\%) and glioblastoma (30\%). Surgery was performed in $73.5 \%$ of patients with $90.2 \%$ of patients receiving chemotherapy. Chemotherapy was initiated either before or during radiation in $80.3 \%$ of patients, and after RT was completed in $4.6 \%$ of patients. The median RT dose was $59.4 \mathrm{~Gy}$ (SD $2.9 \mathrm{~Gy}$ ) starting a median of 4.4 weeks from diagnosis (SD 2.5 weeks). 
Table 2

Patient Demographic and Tumor Characteristics

\begin{tabular}{|c|c|c|}
\hline Variable & Level & $N(\%)=498$ \\
\hline Age at Diagnosis & Median (range) & $15.00(0-21.0)$ \\
\hline \multirow[t]{2}{*}{ Sex } & Male & $269(54.0)$ \\
\hline & Female & $229(46.0)$ \\
\hline \multirow[t]{3}{*}{ Charleson-Deyo Score } & 0 & $451(90.6)$ \\
\hline & 1 & $18(3.6)$ \\
\hline & $\geq 2$ & $29(5.8)$ \\
\hline \multirow[t]{3}{*}{ Race } & White & $395(79.3)$ \\
\hline & Black & 66 (13.3) \\
\hline & Other & $37(7.4)$ \\
\hline \multirow[t]{3}{*}{ Hispanic Origin } & Non-Spanish/Non-Hispanic & $414(83.1)$ \\
\hline & Spanish/Hispanic/Latino & $65(13.0)$ \\
\hline & Unknown & $19(3.8)$ \\
\hline \multirow[t]{3}{*}{ Residence } & Metro & 398 (79.9) \\
\hline & Rural & $31(6.2)$ \\
\hline & Urban & $69(13.9)$ \\
\hline \multirow[t]{5}{*}{ Median Income Quartiles } & $<\$ 38,000$ & $87(17.5)$ \\
\hline & $\$ 38,000-\$ 47,999$ & $129(25.9)$ \\
\hline & $\$ 48,000-\$ 62,999$ & $123(24.7)$ \\
\hline & $\geq \$ 63,000$ & 149 (29.9) \\
\hline & Unknown & $10(2.0)$ \\
\hline \multirow[t]{4}{*}{ Primary Payor } & Private Insurance & $317(63.7)$ \\
\hline & Government Insurance (Medicaid, etc.) & $152(30.5)$ \\
\hline & Not insured & $18(3.6)$ \\
\hline & Unknown & $11(2.2)$ \\
\hline \multirow[t]{3}{*}{ Histology } & Astrocytoma & $276(55.4)$ \\
\hline & Glioblastoma & 149 (29.9) \\
\hline & Gliomas, NOS & $51(10.2)$ \\
\hline
\end{tabular}




\begin{tabular}{|lll|}
\hline Variable & Level & $\mathbf{N}(\%)=\mathbf{4 9 8}$ \\
\hline \multirow{2}{*}{ Tumor Location } & Oligodendrogliomas & $22(4.4)$ \\
& Cerebrum & $373(74.9)$ \\
\cline { 2 - 3 } & Ventricle, NOS & $13(2.6)$ \\
\hline & Cerebellum, NOS & $26(5.2)$ \\
& Overlapping lesion of Brain & $52(10.4)$ \\
\cline { 2 - 3 } & Brain, NOS & $34(6.8)$ \\
\hline Abbreviations: NOS, not otherwise specified & \\
\hline
\end{tabular}


Table 3

Treatment Characteristics

\begin{tabular}{|c|c|c|}
\hline Variable & Level & $N(\%)=498$ \\
\hline \multirow[t]{2}{*}{ Surgical Procedure } & No Surgery & $132(26.5)$ \\
\hline & Resection & $366(73.5)$ \\
\hline \multirow[t]{2}{*}{ Radiation Dose, Gy } & Mean (SD) & $58.50(2.9)$ \\
\hline & Median (range) & $59.40(50-74.0)$ \\
\hline \multirow[t]{2}{*}{ RT Timing, weeks } & Mean (SD) & $5.04(2.47)$ \\
\hline & Median & $4.43(0-12.86)$ \\
\hline \multirow[t]{5}{*}{ Radiation Modality } & Photons, NOS* & $249(49.9)$ \\
\hline & IMRT & $230(46.2)$ \\
\hline & Protons & $14(2.8)$ \\
\hline & Stereotactic Radiosurgery & $2(0.4)$ \\
\hline & Other, NOS & $3(0.6)$ \\
\hline \multirow[t]{4}{*}{ Chemotherapy } & Single agent chemotherapy & $335(67.3)$ \\
\hline & Multi-agent chemotherapy & $98(19.7)$ \\
\hline & Chemotherapy, NOS & $16(3.2)$ \\
\hline & No chemotherapy & $49(9.8)$ \\
\hline Chemotherapy and & Chemotherapy started before or during RT & $400(80.3)$ \\
\hline \multicolumn{3}{|l|}{ RT Sequence } \\
\hline & Chemotherapy started after RT & $23(4.6)$ \\
\hline & Unknown & $75(15.1)$ \\
\hline
\end{tabular}

\section{Overall Survival}

The median follow-up was 19.6 months (Q1-Q3: 11.8-44.5). Overall Survival at 1- and 3-years (95\% Cl) was $78.4 \%(74.4 \%, 81.8 \%)$ and $40.4 \%(35.8 \%, 45.0 \%)$, respectively. On multivariable analysis, older age (hazard ratio (HR) 0.96 (95\% Cl 0.94-0.98), p < 0.001), female gender (HR $0.74(0.58-0.93), p=0.011)$, white race (HR 0.70 (0.50-0.99), $p=0.04)$, RT Delay of $\geq 6$ weeks (HR $0.64(0.47-0.88), p=0.006)$ vs $4-6$ week delay from diagnosis $(0.61(0.46-0.80), p<0.001)$ were significantly associated with a lower rate of death. Glioblastoma vs. astrocytoma histology (HR 1.58 (1.21-2.07), $\mathrm{p}<0.001)$ and RT timing of $<4$ weeks (HR 1.34 (1.03-1.75), $p=0.028)$ vs.4- 6 weeks from diagnosis, and no surgical resection (HR 1.63 
(1.24-2.16), $p<0.001)$ were associated with a significantly higher rate of death. Kaplan-Meier curves of OS according to histology and RT timing are illustrated in Fig. 1. Univariate and multivariable analyses of OS are listed in Table 4. Only statistically significant relationships are included within the table. There was no associated on either univariate or multivariable analysis between OS and Hispanic origin, urban vs. rural residence, median income, year of diagnosis, tumor grade, size of tumor or whether chemotherapy was received. 
Table 4

Univariate and Multivariable Analysis with Overall Survival Univariate Analysis

Multivariable Analysis

\begin{tabular}{|c|c|c|c|c|c|c|}
\hline \multirow{2}{*}{ Covariate } & \multirow[b]{2}{*}{ Level } & \multirow[b]{2}{*}{$\mathbf{N}$} & \multicolumn{2}{|c|}{$\overline{-}$} & \multicolumn{2}{|l|}{ - } \\
\hline & & & $\begin{array}{l}\text { Hazard } \\
\text { Ratio } \\
(95 \% \mathrm{Cl})\end{array}$ & $\begin{array}{l}\text { HR P- } \\
\text { value }\end{array}$ & $\begin{array}{l}\text { Hazard } \\
\text { Ratio } \\
(95 \% \mathrm{Cl})\end{array}$ & $\begin{array}{l}\text { HR P- } \\
\text { value }\end{array}$ \\
\hline Age at Diagnosis & & 498 & $\begin{array}{l}0.95 \\
(0.94- \\
0.97)\end{array}$ & $<.001$ & $\begin{array}{l}0.96 \\
(0.94- \\
0.98)\end{array}$ & $<.001$ \\
\hline \multirow[t]{2}{*}{ Sex } & Female & 229 & $\begin{array}{l}0.78 \\
(0.62- \\
0.97)\end{array}$ & 0.025 & $\begin{array}{l}0.74 \\
(0.58- \\
0.93)\end{array}$ & 0.011 \\
\hline & Male & 269 & REF & - & REF & - \\
\hline \multirow[t]{3}{*}{ Race } & White & 395 & $\begin{array}{l}0.79 \\
(0.58- \\
1.08)\end{array}$ & 0.145 & $\begin{array}{l}0.70 \\
(0.50- \\
0.99)\end{array}$ & 0.042 \\
\hline & Other & 37 & $\begin{array}{l}0.82 \\
(0.49- \\
1.39)\end{array}$ & 0.460 & $\begin{array}{l}0.77 \\
(0.45- \\
1.34)\end{array}$ & 0.358 \\
\hline & Black & 66 & REF & - & REF & - \\
\hline \multirow[t]{3}{*}{$\begin{array}{l}\text { Charlson-Deyo } \\
\text { Score }\end{array}$} & $2+$ & 29 & $\begin{array}{l}1.89 \\
(1.25- \\
2.85)\end{array}$ & 0.002 & & \\
\hline & 1 & 18 & $\begin{array}{l}1.49 \\
(0.85- \\
2.61)\end{array}$ & 0.160 & & \\
\hline & 0 & 451 & REF & - & & \\
\hline \multirow[t]{4}{*}{ Primary Payor } & Private Insurance & 317 & $\begin{array}{l}0.72 \\
(0.57- \\
0.91)\end{array}$ & 0.006 & & \\
\hline & Not insured & 18 & $\begin{array}{l}0.78 \\
(0.42- \\
1.44)\end{array}$ & 0.421 & & \\
\hline & Insurance Status Unknown & 11 & $\begin{array}{l}0.65 \\
(0.28- \\
1.47)\end{array}$ & 0.299 & & \\
\hline & $\begin{array}{l}\text { Government Insurance } \\
\text { (Medicaid, Medicare, Other) }\end{array}$ & 152 & REF & - & & \\
\hline
\end{tabular}




\begin{tabular}{|c|c|c|c|c|c|c|}
\hline \multirow[b]{2}{*}{ Histology } & \multirow[b]{2}{*}{ Glioblastoma } & \multirow[b]{2}{*}{149} & \multicolumn{2}{|c|}{ Univariate Analysis } & \multicolumn{2}{|c|}{$\begin{array}{l}\text { Multivariable } \\
\text { Analysis }\end{array}$} \\
\hline & & & $\begin{array}{l}1.46 \\
(1.15- \\
1.86)\end{array}$ & 0.002 & $\begin{array}{l}1.58 \\
(1.21- \\
2.07)\end{array}$ & $<.001$ \\
\hline & Gliomas & 51 & $\begin{array}{l}0.72 \\
(0.48- \\
1.07)\end{array}$ & 0.108 & $\begin{array}{l}0.87 \\
(0.56- \\
1.36)\end{array}$ & 0.459 \\
\hline & Oligodendrogliomas & 22 & $\begin{array}{l}0.59 \\
(0.32- \\
1.09)\end{array}$ & 0.092 & $\begin{array}{l}0.61 \\
(0.32- \\
1.16)\end{array}$ & 0.177 \\
\hline & Astrocytomas & 276 & REF & - & REF & - \\
\hline \multirow[t]{5}{*}{ Primary Site } & C719-Brain, NOS & 34 & $\begin{array}{l}1.45 \\
(0.94- \\
2.25)\end{array}$ & 0.097 & & \\
\hline & $\begin{array}{l}\text { C718-Overlapping lesion of } \\
\text { brain }\end{array}$ & 52 & $\begin{array}{l}1.13 \\
(0.79- \\
1.60)\end{array}$ & 0.504 & & \\
\hline & C716-Cerebellum, NOS & 26 & $\begin{array}{l}1.57 \\
(1.01- \\
2.46)\end{array}$ & 0.047 & & \\
\hline & C715-Ventricle, NOS & 13 & $\begin{array}{l}0.79 \\
(0.35- \\
1.79)\end{array}$ & 0.579 & & \\
\hline & C710-Cerebrum & 373 & REF & - & & \\
\hline \multirow[t]{2}{*}{$\begin{array}{l}\text { Surgical } \\
\text { Procedure }\end{array}$} & No Surgery & 132 & REF & - & $\begin{array}{l}1.63 \\
(1.24- \\
2.16)\end{array}$ & $<.001$ \\
\hline & Resection & 366 & $\begin{array}{l}0.51 \\
(0.40- \\
0.65)\end{array}$ & $<.001$ & REF & - \\
\hline RT Timing Delay & Weeks from diagnosis & 495 & $\begin{array}{l}0.87 \\
(0.83- \\
0.92)\end{array}$ & $<.001$ & & \\
\hline \multirow[t]{3}{*}{ RT Delay } & RT Delay 6 or more Weeks & 133 & REF & - & $\begin{array}{l}0.64 \\
(0.47- \\
0.88)\end{array}$ & 0.006 \\
\hline & RT Timing N/A & 3 & $\begin{array}{l}1.91 \\
(0.47- \\
7.79)\end{array}$ & 0.370 & $\begin{array}{l}1.05 \\
(0.24- \\
4.55)\end{array}$ & 0.952 \\
\hline & $\begin{array}{l}\text { RT Delay Less Than } 4 \\
\text { Weeks }\end{array}$ & 186 & $\begin{array}{l}2.25 \\
(1.68- \\
3.02)\end{array}$ & $<.001$ & $\begin{array}{l}1.34 \\
(1.03- \\
1.75)\end{array}$ & 0.028 \\
\hline
\end{tabular}




\begin{tabular}{|c|c|c|c|c|c|c|}
\hline & & & \multicolumn{2}{|c|}{ Univariate Analysis } & \multicolumn{2}{|c|}{$\begin{array}{l}\text { Multivariable } \\
\text { Analysis }\end{array}$} \\
\hline & RT Delay 4-6 Weeks & 176 & $\begin{array}{l}1.68 \\
(1.24- \\
2.27)\end{array}$ & $<.001$ & REF & - \\
\hline \multirow[t]{3}{*}{$\begin{array}{l}\text { Sequence of } \\
\text { Chemo and RT } \\
\text { Start }\end{array}$} & Unknown & 75 & $\begin{array}{l}2.66 \\
(1.35- \\
5.22)\end{array}$ & 0.005 & & \\
\hline & $\begin{array}{l}\text { Chemo started } \\
\text { before/during RT }\end{array}$ & 400 & $\begin{array}{l}1.88 \\
(1.00- \\
3.53)\end{array}$ & 0.051 & & \\
\hline & $\begin{array}{l}\text { Chemo started after RT } \\
\text { done }\end{array}$ & 23 & REF & - & & \\
\hline
\end{tabular}

\section{Impact of RT Parameters}

As previously described, patients treated with earlier RT timing of $<6$ weeks from diagnosis demonstrated a significantly increased risk of death on both univariate and multivariate analysis (Table 4, Fig. 1b). To evaluate whether this finding could be attributed to patients not undergoing surgical resection receiving earlier RT, the impact of RT timing was also evaluated in the subgroup of patients who underwent surgical resection. Among the 366 patients receiving surgery, both RT delay of $<4$ week (HR 2.52 (1.70$3.72), p<0.001)$ and RT delay of $4-6$ weeks $(2.08(1.43-3.04), p<0.001)$ were similarly associated with an increased risk of death as opposed to RT delay of $>6$ weeks on multivariable analysis.

Radiation dose escalation $\geq 59.4$ Gy versus RT dose $<59.4$ Gy was not significantly associated with OS on univariate (HR $0.80(0.62-1.04), p=0.093)$ or multivariable analysis (HR $0.99(0.74-1.32), p=0.942)$. Patients who received escalated dose RT were more likely to have glioblastoma histology $(p=0.004)$ and be of greater age $(p<0.001)$, and less likely to have a Charles-Deyo Score of $\geq 2(p=0.012)$ (results not shown on tables). There was also no association between OS and RT modality (Protons vs. IMRT vs. 3-D conformal therapy or external beam/photons NOS).

\section{Discussion}

Pediatric HGG are a heterogenous group of patients that comprise a small fraction of pediatric cancer, but account for a majority of pediatric cancer deaths under the age of 20 . Over the past 50 years multiple treatment options have been investigated including gross tumor resection, radiation therapy, and biological and chemotherapy agents. However, the overall prognosis for pediatric HGG patients remains poor with outcomes highly dependent on the tumor histology and patients with glioblastoma demonstrating the worst overall survival. 
In this study, most pediatric HGG patients received trimodality therapy, including surgical resection, chemotherapy and radiation therapy in accordance with current standard practice. Tumor resection was performed in $73.5 \%$ of patients and was associated with improved overall survival on multi-variable analysis. The Children's Cancer Study Group (CCG) 945 study has previously demonstrated the importance of surgical resection. Patients with greater than $90 \%$ gross tumor resection had improved 5year progression free survival of $35 \%$ compared to only $17 \%$ for those with less than $90 \%$ tumor resection $[5,8]$. While the occurrence of surgical resection was an important prognostic variable in this analysis, the extent of the resection was not available for the majority of patients in this dataset and so was not analyzed here. Complete resection remains difficult for pediatric HGG due to the tumor volumes being illdefined, irregularly shaped, invasive, or in situations in which the surgeon cannot complete a safe resection (e.g. midline tumors) $[9,10]$.

Radiotherapy is an essential part of the treatment for pediatric HGG. Between 1966 and 1975, multiple Brain Tumor Study Group protocols evaluated the efficacy of RT. Patients who received no RT were compared to groups receiving escalating doses ranging from 45Gy to 60Gy. Patients that received no RT had a median survival of 18.0 weeks while those that receive $50 \mathrm{~Gy}$ to $60 \mathrm{~Gy}$ showed a median survival of 28.0 weeks and 42.0 weeks, respectively [11]. Though different dose fractionations have been investigated, the use of hyperfractionation or accelerated fractionation RT dose delivery has not improved outcomes [12], and therefore, the conventional dose of 54-60Gy total dose in 1.8-2.0Gy per day for approximately 6 weeks remains the current standard of care for pediatric HGG.

More recently, RT dose escalation using advanced IMRT or proton therapy techniques to deliver a simultaneous integrated boost of 75Gy has been studied in adult glioblastoma patients with favorable outcomes demonstrated on small single institution studies $[13,14]$. This concept is currently being compared to conventional RT doses in a randomized fashion for adult glioblastoma patients receiving concurrent and adjuvant temozolamide in the NRG Oncology BN001 trial (NCT02179086). We sought to evaluate whether a RT dose response could be detected among pediatric HGG patients in this analysis. Patients in this study receive a median RT dose of 59.4Gy. Though a trend with improved OS and higher radiation dose was seen on univariate analysis, the results were not statistically significant, and no association was found on multi-variable analysis. Further, more-detailed analyses would be required to evaluate the potential impact of RT dose escalation on tumor control and patterns of failure in pediatric HGG, which is not feasible in this population-based dataset.

The results of this study demonstrate that initiation of RT earlier than 6 weeks after diagnosis is associated with a higher rate of death, a finding that was true among all patients and when limited to the subcohort of patients who underwent surgical resection. It should be noted that all patient received RT within 90 days of diagnosis, as initiation of treatment later than that was considered an exclusion criteria. This is a novel finding that to our knowledge has not been previously identified among pediatric HGG, though recent studies in adult glioblastoma using the NCDB found similar results [15]. This study is limited in its retrospective design and the finding could be attributed to selection bias with patients demonstrating more aggressive histologies, more concerning imaging findings or more aggressive 
clinical course initiating RT earlier. We attempted to minimize potential bias by evaluating the impact of RT timing among the subgroup of patient receiving surgical resection only, and the same results were found. However, the extent of surgical resection is unknown and patients with sub-total resection and a higher burden of disease remaining after surgery may have poorer outcomes and may also been more likely to receive earlier initiation of RT. Additional prognostic variables, such as tumor molecular characteristics, are unknown and may have impacted the study results in unknown ways. While there is no clear clinical hypothesis to explain why RT initiation at $>6$ weeks from diagnosis would lead to improved outcomes as compared with 4-6 weeks from diagnosis in and of itself, it is reasonable to conclude that RT timing of $>6$ weeks may not be detrimental for some pediatric HGG patients.

No significant difference in outcomes were seen between patients treated with photons vs. proton therapy, though only $2.8 \%$ of patients in this cohort received proton therapy. Proton therapy is becoming increasingly available and utilized for pediatric brain tumor patients in the United States. Though outcome data for pediatric HGG patients treated with proton therapy is limited, these results suggest there is no detriment to the use of proton therapy as opposed to IMRT or 3D conformal photon techniques in pediatric HGG.

\section{Conclusions}

Outcomes for pediatric HGG are poor and novel treatment approaches are needed to improve outcomes. Glioblastoma histology, absence of surgical resection, and RT timing of less than 6 weeks from diagnosis were significantly associated with an increased risk of death in this population-based analysis. Early initiation of RT may be associated with poor prognostic factors not available in this population-based dataset. No benefit to RT dose escalation above 59.4Gy or difference in outcomes according to whether RT was delivered with photon or proton therapy was found.

\section{Declarations}

Funding Source: Research reported in this publication was supported in part by the Winship Research Informatics shared resource of Winship Cancer Institute of Emory University and $\mathrm{NIH} / \mathrm{NCl}$ under award number P30CA138292. The content is solely the responsibility of the authors and does not necessarily represent the official views of the National Institutes of Health.

Conflicts of interest: The authors have no conflicts of interest to declare that are relevant to the content of this article.

Data Availability: The datasets generated during and/or analyzed are available in the National Cancer Database (NCDB).

Author Contribution: All authors contributed to the study conception and design. Material preparation, data collection and analysis were performed by Dr. Bree Eaton, Dr. Christopher Williamson, Mr. Renjian Jiang, and Ms. Shayla Williamson. The final draft of the manuscript was written by Dr. Christopher 
Williamson and all authors commented on previous versions of the manuscript. All authors read and approved the final manuscript.

Authorship of this manuscript is in accordance with the International Committee of Medical Journal Editors recommendations that each author have a substantial contribution to the conception or design of the work, the drafting and revising of critically important intellectual content, the final approval of the published version, and agree to be accountable for all questions related to accuracy or integrity of the published work.

Ethics and consent to participate and publish: All data used for the purposes of this manuscript were obtained from the National Cancer Database, jointly sponsored by the American College of Surgeons and the American Cancer Society. Patient information was collected in accordance with the institutional and national standards and use of patient data was approved by Emory University ethics committee.

\section{References}

1. Ostrom QT, Gittleman H, Fulop J, et al. CBTRUS Statistical Report: Primary Brain and Central Nervous System Tumors Diagnosed in the United States in 2008-2012. Neuro Oncol 2015;17 Suppl 4:iv1-iv62.

2. Braunstein S, Raleigh D, Bindra R, Mueller S, Haas-Kogan D. Pediatric high-grade glioma: current molecular landscape and therapeutic approaches. J Neurooncol 2017;134:541-9.

3. Louis DN, Perry A, Reifenberger G, et al. The 2016 World Health Organization Classification of Tumors of the Central Nervous System: a summary. Acta Neuropathol 2016;131:803-20.

4. Stupp R, Mason WP, van den Bent MJ, et al. Radiotherapy plus concomitant and adjuvant temozolomide for glioblastoma. N Engl J Med 2005;352:987-96.

5. Cohen KJ, Pollack IF, Zhou T, et al. Temozolomide in the treatment of high-grade gliomas in children: a report from the Children's Oncology Group. Neuro Oncol 2011;13:317-23.

6. Sposto R, Ertel IJ, Jenkin RD, et al. The effectiveness of chemotherapy for treatment of high grade astrocytoma in children: results of a randomized trial. A report from the Childrens Cancer Study Group. J Neurooncol 1989;7:165-77.

7. Liu Y, Nickleach DC, Zhang C, Switchenko JM, Kowalski J. Carrying out streamlined routine data analyses with reports for observational studies: introduction to a series of generic SAS ((R)) macros. F1000Res 2018;7:1955.

8. Finlay JL, Boyett JM, Yates AJ, et al. Randomized phase III trial in childhood high-grade astrocytoma comparing vincristine, lomustine, and prednisone with the eight-drugs-in-1-day regimen. Childrens Cancer Group. J Clin Oncol 1995;13:112-23. 
9. Rodriguez Gutierrez D, Jones C, Varlet P, et al. Radiological Evaluation of Newly Diagnosed NonBrainstem Pediatric High-Grade Glioma in the HERBY Phase II Trial. Clin Cancer Res 2020;26:1856-65.

10. El-Ayadi M, Ansari M, Sturm D, et al. High-grade glioma in very young children: a rare and particular patient population. Oncotarget 2017;8:64564-78.

11. Walker MD, Strike TA, Sheline GE. An analysis of dose-effect relationship in the radiotherapy of malignant gliomas. Int J Radiat Oncol Biol Phys 1979;5:1725-31.

12. Fallai C, Olmi P. Hyperfractionated and accelerated radiation therapy in central nervous system tumors (malignant gliomas, pediatric tumors, and brain metastases). Radiother Oncol 1997;43:235-46.

13. Tsien $\mathrm{Cl}$, Brown D, Normolle D, et al. Concurrent temozolomide and dose-escalated intensitymodulated radiation therapy in newly diagnosed glioblastoma. Clin Cancer Res 2012;18:273-9.

14. Kim MM, Speers C, Li P, et al. Dose-intensified chemoradiation is associated with altered patterns of failure and favorable survival in patients with newly diagnosed glioblastoma. J Neurooncol 2019;143:313-9.

15. Press $\mathrm{RH}$, Shafer SL, Jiang R, et al. Optimal timing of chemoradiotherapy after surgical resection of glioblastoma: Stratification by validated prognostic classification. Cancer 2020;126:3255-64.

\section{Figures}

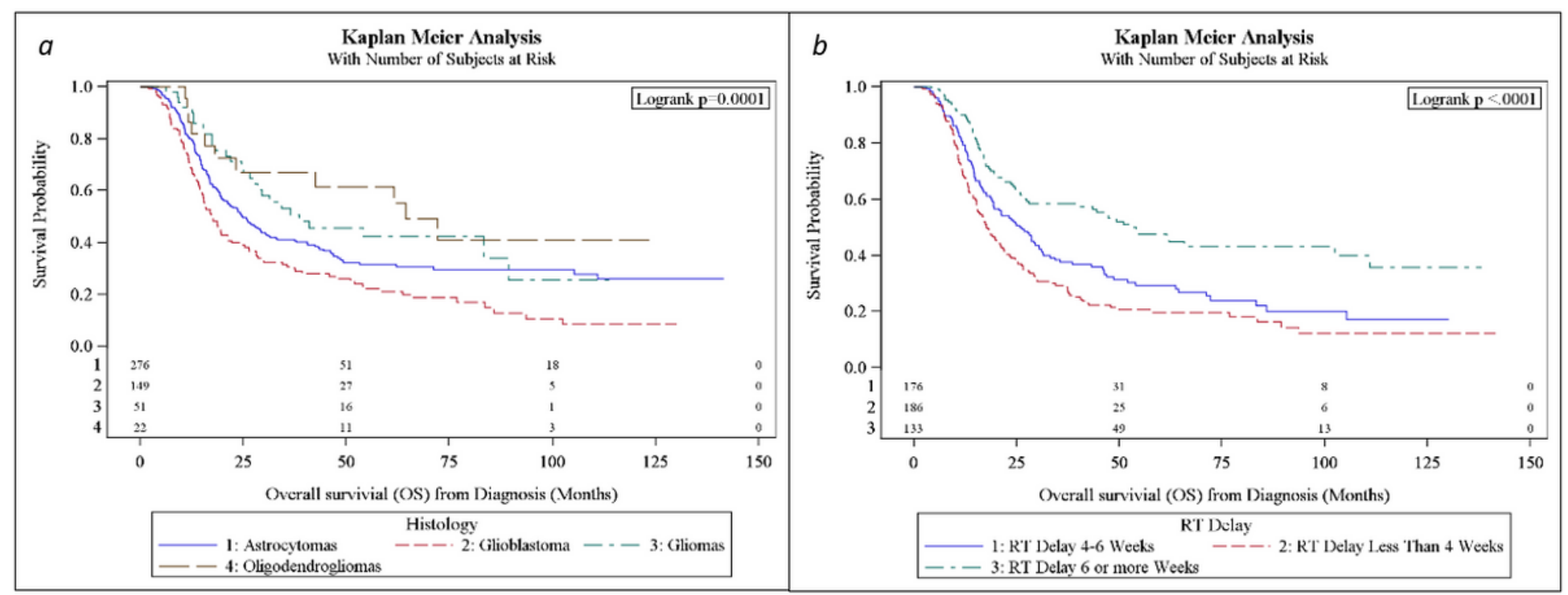

Figure 1

Kaplan Meier Analysis of Overall survival according to tumor histology (a) and timing of RT initiation from diagnosis (b). 